\title{
Common Features of Giant Prolactinoma and Paranasal Neuroendocrine Carcinoma-Case Report
}

Adriana GOGOI ${ }^{1}$, Lidia RADOMIR ${ }^{1}$, Ana Maria HILMA ${ }^{3}$, Cristina STANCU ${ }^{1}$, Simona JERCALAU ${ }^{1}$, Maria $\mathrm{PICU}^{4}$, Corin BADIU ${ }^{1,2}$

1 "CI Parhon" National Institute of Endocrinology, Bucharest, Romania

2 "Carol Davila" University of Medicine and Pharmacy, Bucharest, Romania

3 "Elias" Emergency University Clinic Hospital Bucharest

4 "C.M.I. dr Maria Picu" Craiova, Romania

\section{Introduction}

Giant prolactinoma is a very rare tumor that due to its massive extension into surrounding structures can present more often with neurological complications such as visual defects, cranial nerve paresis or even hydrocephalus, unlike the classic prolactinoma presentation with amenorrhea, infertility and galactorrhea. On CT/MRI exams it can present as aggressive skull base tumor and its immunohistochemistry (IHC) may have common features with neuroendocrine neoplasms.

\section{Case Report}

We present the case of a patient with giant prolactinoma first misdiagnosed as a paranasal sinus neuroendocrine carcinoma (PSNEC).

A 43 y.o. woman was diagnosed with a large destructive tumor of the skull base measuring $7.6 \mathrm{~cm}$ in the clinical context of diplopia, facial paresthesia and right retroocular pain. CT scan revealed sella turcica involvement, bilateral cavernous sinus, right sphenoid sinus and right nasal cavity extension, and compressive mass effect on the right temporal lobe and brainstem. She was known with secondary amenorrhea since 27 y.o.

She underwent a biopsy and the pathology and IHC evaluation pleaded for PSNEC. IHC was diffuse positive for synaptophysin and CD 56, focally positive for chromogranin, negative for $S-100$ and ki 67 was positive in aprox $8 \%$ of the cells. Prolactin staining was not part of the initial IHC evaluation.

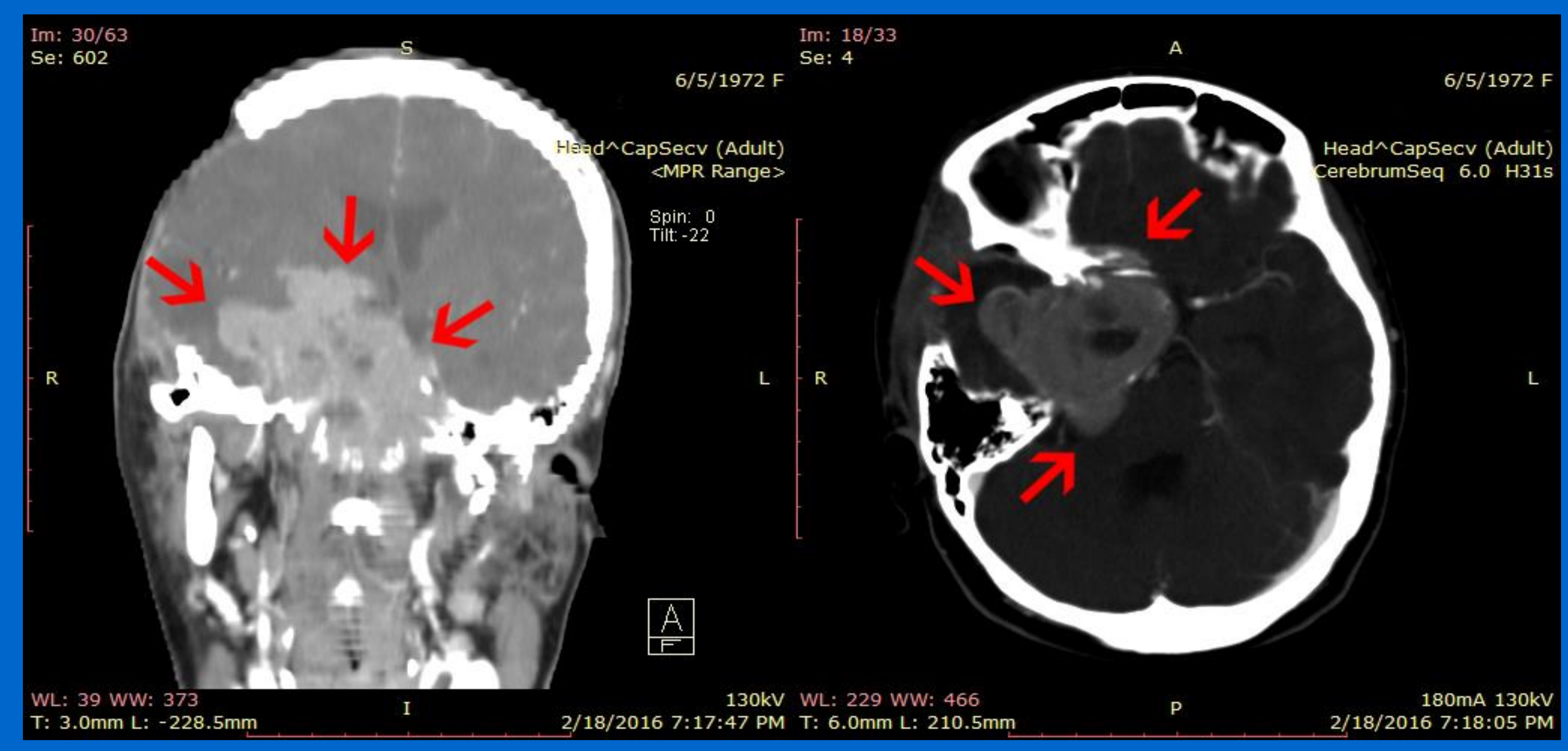

\section{Investigations and Management}

Awaiting a decision on surgery vs radiation therapy, endocrine assessment revealed a very high prolactin $34.311 \mathrm{ng} / \mathrm{ml}(\mathrm{ref} 4.79-23.3 \mathrm{ng} / \mathrm{ml})$, low gonadotropins $(\mathrm{FSH}=6.5 \mathrm{uUI} / \mathrm{ml}, \mathrm{LH}=0.81 \mathrm{uUI} / \mathrm{ml})$ indicating hypogonadotropic hypogonadism, a normal pituitary function in rest $(\mathrm{TSH}=$ $1.31 \mathrm{uUI} / \mathrm{ml}, \mathrm{fT} 4=12.26 \mathrm{pmol} / \mathrm{l}, \mathrm{ACTH}=30.26 \mathrm{pg} / \mathrm{ml}$, cortsol after stmulation with $1 \mathrm{mg}$ Synachten> $60 \mathrm{ug} / \mathrm{dl}, \mathrm{IGF} 1=219.2 \mathrm{ng} / \mathrm{ml} \mathrm{ref} 95-251)$, and slightly elevated plasma CgA, NSE and $24 \mathrm{~h}$ urinary 5-HIIA. She was also presenting bilateral galactorrhea, VI nerve paresis RE, nasal RE and nasal and temporal LE visual field impairment.

Reviewing the diagnosis, IHC staining was repeated and it was strongly positive for PRL and negative for GH.

Therapeutic decision involved $2 \mathrm{mg} /$ week cabergoline and after 2 months prolactin was $192 \mathrm{ng} / \mathrm{ml}$; the dose was increased at 3 $\mathrm{mg} /$ week and after 1 month PRL was $64.32 \mathrm{ng} / \mathrm{ml}$ with total normalization of visual fields, remission of the galactorrhea and evident clinical improvement reported by the patient. The hypogonadotropic hypogonadism with secondary amenorrhea persisted, but the rest of the pituitary function remains normal, with ITT excluding cortico and somatotrophic deficiencies.

After 3 months of Cabergoline treatment, MRI scan shows also a tumoral response.

\section{Discussion}

Prolactinomas can express common neuroendocrine markers found in neoplasms with neuroendocrine differentiation like IHC staining for chromogranin and synaptophysin, but it's important to make the right diagnosis as in the case of prolactionomas, dopamine agonists are the treatment and it can normalize the PRL and reduce the tumor size with important clinical improvement.
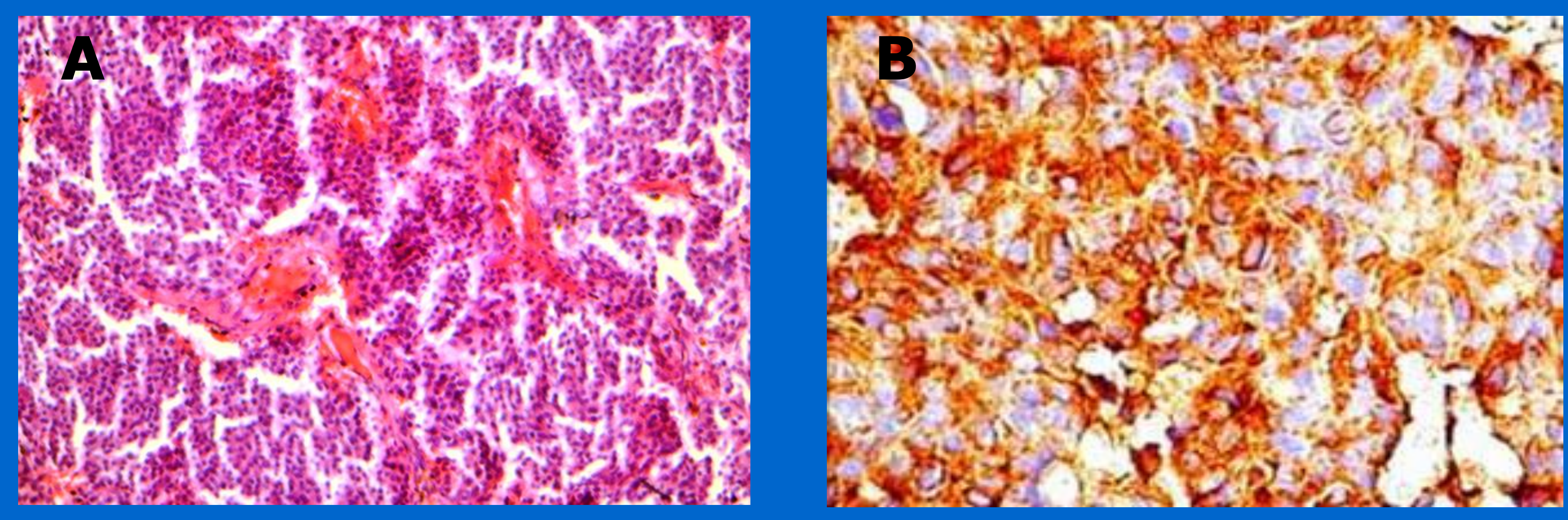

Prolactin - secreting adenoma. A: Hematoxylin-eosin stain. B: Immunochemistry shows reactivity for PRL

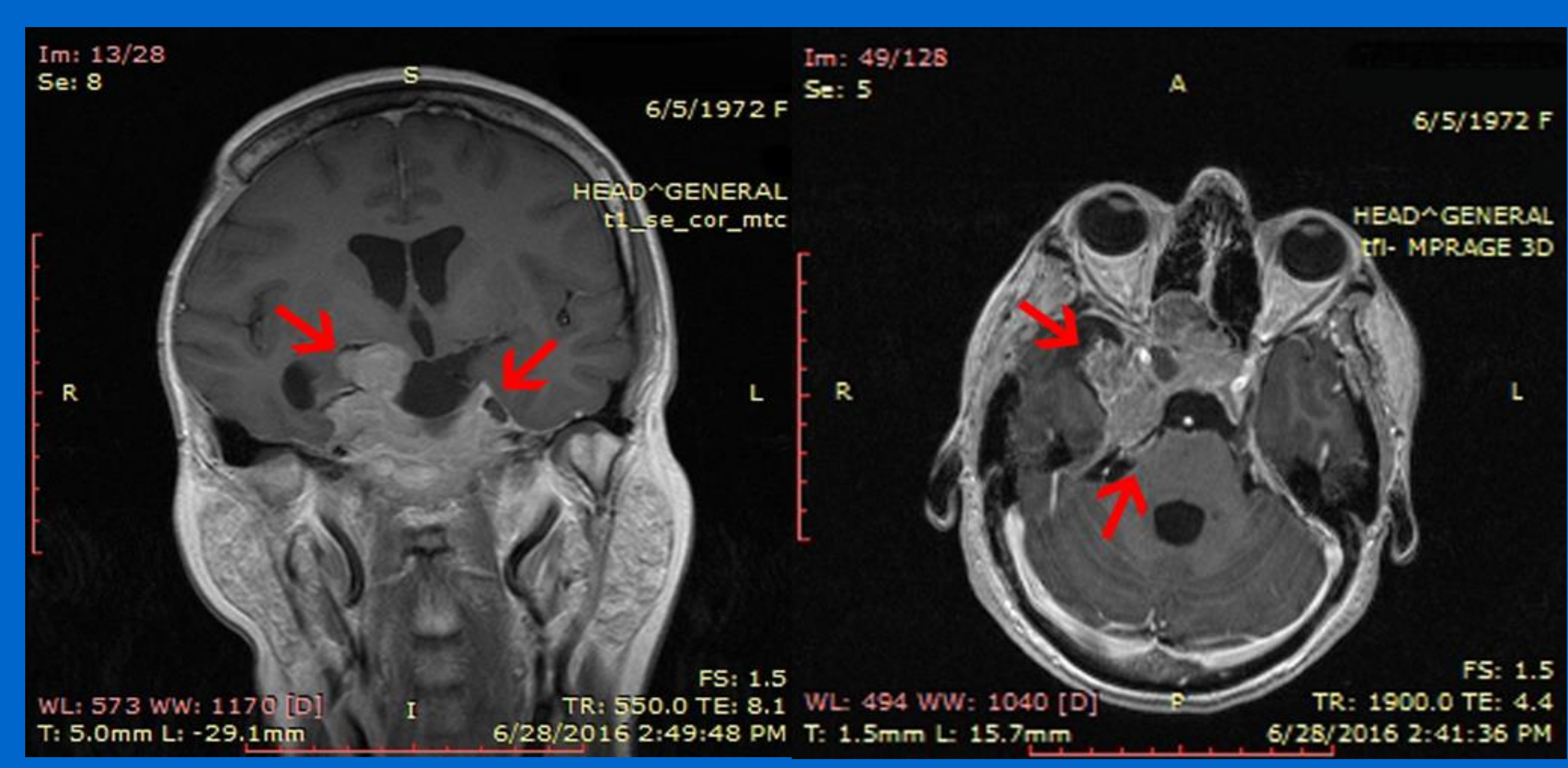

\section{Conclusion}

Evaluation of large skull base tumors must include full pituitary hormonal profile due to the giant prolactinoma's atypical presentation and its common IHC features with neuroendocrine neoplasms. 